\title{
LAUGHTER IN BILL CLINTON'S MY LIFE (2004) INTERVIEWS
}

\author{
Daniel C. O'Connell and Sabine Kowal
}

\begin{abstract}
Two types of laughter of Bill Clinton and his interviewers - as an overlay of words spoken laughingly and laughter of the ha-ha sort - were investigated. The corpus consisted of 13 media interviews, all of which took place after the publication of his book My life (2004). Bill Clinton's laughter was found to be dominantly an overlay of words spoken laughingly, whereas his interviewers' laughter was dominantly of the ha-ha sort. In general, ha-ha laughter occurred as interruption or back channeling $30 \%$ of the time and hence did not necessarily punctuate speech during pauses at the end of phrases and sentences as claimed by Provine (1993). Analyses of the topics laughed about indicated that Bill Clinton laughed mainly about his personal problems and his personal life, whereas his interviewers laughed mainly about politics and Clinton's book. Accordingly, Bill Clinton's laughter in these interviews was peculiarly monological and self-absorbed: It was generally not shared with the interviewers, either simultaneously or successively, in a genuinely contagious and dialogical fashion. Laughter did not follow upon "banal comments," as Provine (2004: 215) has claimed, nor reflect either the "nonseriousness" claimed by Chafe (2003a, b) or the uncensored spontaneity noted by Provine (2004: 216). Instead, laughter reflected in every instance the personal perspectives of both Bill Clinton and his interviewers and was used, especially by Clinton, as a deliberate, sophisticated, and rhetorical device.
\end{abstract}

Keywords: Laughter, Media interviews, Perspectives, Rhetoric, Dialogue.

\section{Introduction}

An empirical article on laughter can hardly begin anywhere other than with a recent overall article on laughter by Provine (2004); even Time magazine (Kluger 2005) has drawn on his work. After a long drouth in research on this topic, there has been a notable resurgence toward the end of the last century. Two recent books in particular have also presented general overviews of the field (Glenn 2003; Provine 2000) from a sociolinguistic and a psychological viewpoint, respectively. Somewhat earlier, Apte (1985) provided an overview from an anthropological standpoint, and Stearns (1972) approached laughter as a pathological phenomenon from a medical point of view.

One historical preoccupation that has diverted researchers over the centuries from a genuine empirical interest in laughter itself - as a behavior worthy of investigation in its own right - has been its assumed relationship to humor and the comical. In fact, traditional literature prominently reflects the second and archaic meaning of laughter given by Merriam-Webster's collegiate dictionary (11 ${ }^{\text {th }}$ ed., 2003: 704), rather than the first and current meaning: " 1 : A sound of or as if of laughing 2 archaic : a cause of merriment." Citations from a number of works manifest this confusion. For example, the philosopher Bergson (1914) made the archaic meaning clear even in the title of his 
book on Laughter: An essay on the meaning of the comic. In a study on the phylogeny of laughter and smiling, van Hooff (1972: 209) characterized the archival literature on laughter as follows: "The essence of the comical, the ludicrous, has been the main and sometimes the sole concern of many students of laughter." More recently, a theological presentation has used the term laughter similarly (Kuschel 1994), and a cultural tract has maintained the same meaning in a German work entitled Lachen: Über westliche Zivilisation (Bohrer \& Scheel 2002; in English, Laughter: On western civilization). Finally, a study by White (1988: 75) has expressed the synonymy of laughter and humor in her title: "Liberating laughter: An inquiry into the nature, content, and functions of feminist humor."

Another manifestation of the confusion between laughter as a behavior and laughter as "a cause of merriment" (Merriam-Webster's collegiate dictionary, $11^{\text {th }}$ ed., 2003: 704 ) is to be found in an analysis of the overlapping references across the two most recent texts on laughter mentioned above (Glenn 2003; Provine 2000): Only 20 of the 463 references are common to both books. Of these 20 entries, 12 were published well before Apte's (1985) anthropological study of laughter, but only six of these 12 are to be found therein. These six references (Chapman 1976; Coser 1960; Darwin 1872/1965; Foot \& Chapman 1976; Freud 1905/1976; and Koestler 1964) are hardly an adequate foundation for our empirical knowledge of laughter. In addition, Stearns' (1972) medical treatment of laughter was too early to contain all but four of these six references. Still, only one of them - the reference to Freud - is actually referenced in Stearns. Freud (1905/1936), however, as his very title -- Jokes and their relation to the unconscious -- shows, is a throwback to the traditional notion of the synonymy of laughter and humor.

Recent empirical research has indicated that the relationship of the ha-ha type of laughter to humor is at best tenuous. Provine (2004: 215) reported that "only 10 to $15 \%$ of prelaugh comments were remotely humorous"; for the rest, they were typically "banal comments." But Provine's (1993: 293) methodology limited this probe to "within 1 s preceding the onset of the initial laughter." These several syllables obviously excluded any appreciable context. O'Connell and Kowal (2004) took a broader verbal context into account and found that comments preceding ha-ha laughter in political media interviews of Hillary Clinton were not at all banal, but rather pointedly politically relevant. And so, although the relationship of laughter to humor and the comical as such may be tenuous, the topics of discourse that elicit laughter may be quite serious. This is not to say that the literal import of a speaker's verbalizations is necessarily paralleled in the laughter. Quite the contrary, the laughter may countermand, alter, or nuance the spoken words in subtle ways. Chafe (2003a: 41) has asserted to the contrary that laughter is associated with "the feeling of nonseriousness," and this feeling is "pleasant." Harris (1999: 345), however, has questioned the necessary association of laughter with pleasantness: "The laughter-pleasure connection is an uncertain one." More specifically, Keltner and Bonanno (1997: 687) have associated laughter during bereavement with a distancing from distress and an enhancement of social relations.

Nor is it necessarily the case that "laughter punctuates speech," i.e., occurs "during pauses at the end of phrases or sentences" (Provine 1993: 291). Again, O'Connell and Kowal (2004: 475) found that Hillary Clinton in her interviews used ha-ha laughter as a sort of back channeling wherever in the course of her interviewers' questions she wished. 
Most of the empirical research on laughter has explicitly engaged primarily the haha type (e.g., Provine 2004: 216; see also Chafe 2003a and O'Connell \& Kowal 2004). Nwokah, Hsu, Davies, and Fogel (1999) have noted this limitation and also have found that up to $50 \%$ of their infant-directed laughter on the part of mothers was in fact laughter produced simultaneously with speech or, as they refer to it, speech-laughs (see also Trouvain 2001).

There are still further problems with an all too specific definition of laughter as "instinctive, contagious, stereotyped, unconsciously controlled, social play vocalization" (Provine 2004: 215). This definition can be compared with Trouvain's (2003: 2793): "an every-day, human-specific, affective, nonverbal vocalization." One very basic problem with both these definitions is that they could define crying in the same terms. Moreover, Provine (2000: 43) would wish to characterize laughter as "the quintessential human social signal," but Glenn (2003: 14) has reminded us that laughter can also be a "solitary" form of expression.

According to Psathas (1979: 79), prior to the research of Gail Jefferson (no date, 1974, 1979), there were "no studies of the organization of laughter in interaction" to be found in the research literature. To date, a dearth of empirical studies across heterogeneous situations still prevails. We still need to know: (1) to what extent laughter is related to ongoing banal or non-banal discourse topics; (2) which of these topics are most saliently related to laughter; (3) to what extent laughter occurs as an overlay on spoken words themselves or as the ha-ha sort; (4) where and when laughter occurs in relation to ongoing speech: during phrases and sentences or after phrases and sentences, i.e., during speaking or during pauses; (5) to what extent laughter serves as "an unplanned response to social, cognitive, and linguistic cues" (Provine 2004: 216) or as a perspectival rhetorical device; and (6) to what extent laughter is mutually shared by interlocutors, i.e., by eliciting laughter or by joining in the laughter of the interlocutor.

The following research is presented within the context of a perspectival theory of language use. Laughter is considered to be "always a nonverbal expression of personal perspective" (O'Connell \& Kowal 2004: 476), not just "spontaneous and relatively uncensored," manifesting, therefore, "our true feelings" (Provine 2004: 216). Indeed, such a concept is too narrow as a general theory of laughter applicable to a variety of situations. We set out from the hypothesis that

Perspectivity extends to the use of nonverbal as well as verbal elements of an utterance. Hence, laughter is to be considered perspectival - a nonverbal, vocal communication of personal views. (O’Connell \& Kowal 2004: 465)

In the context of a political interview, this translates into the hypothesis that laughter may be used in a deliberate, sophisticated, and rhetorical manner. Such an hypothesis would appear to be in accord with Trouvain's (2001) assertion that laughter reflects attitudes, but not in accord with the generalization of Provine (2004: 216):

Laughter is spontaneous and relatively uncensored, thus showing our true feelings. Laughter, like crying, is difficult to produce on command and, therefore, an honest signal. We cannot deliberately activate the brain's mechanism for affective expression - laughter is an unplanned response to social, cognitive, and linguistic cues.

Provine (2004: 216) could well designate our position as "an error of intentionality (Provine 2000), falsely assuming that laughter is a choice and under strong voluntary 
control." However, our contention is that the deliberate, sophisticated, and rhetorical use of laughter does not imply immediate, direct conscious control.

\section{Methods}

The following research has been planned to parallel our investigation (O'Connell \& Kowal 2004) of six media interviews of Hillary Clinton after the publication of her Living history (2003). In the present instance, we investigated 13 media (TV and radio) interviews of Bill Clinton after the publication of his My life (2004). This data base is presented in Table 1 in chronological sequence and with notation of the interviewer's gender, the medium (TV or radio [R]), the network or channel that produced the

Table 1

The Data Base of the Present Research: Television (TV) and Radio (R) Interviews of Former President Bill Clinton on the Occasion of the Publication of his Book My life (2004), Listed Chronologically

\begin{tabular}{lllll}
\hline Interviewer & Gender & Medium & Channel & Date \\
\hline Dan Rather & M & TV & CBS & $6 / 20 / 04$ \\
David Dimbleby & M & TV & BBC & $6 / 22 / 04$ \\
Oprah Winfrey & F & TV & NBC & $6 / 22 / 04$ \\
Charles Gibson & M & TV & ABC & $6 / 23 / 04$ \\
Charlie Rose & M & TV & PBS & $6 / 23 / 04$ \\
Katie Couric & F & TV & NBC & $6 / 23,24 / 04$ \\
Juan Williams & M & R & NPR & $6 / 23,24 / 04$ \\
Larry King & M & TV & CNN & $6 / 24 / 04$ \\
Terry Gross & F & R & NPR & $6 / 24 / 04$ \\
Harry Smith & M & TV & CBS & $6 / 26 / 04$ \\
Jim Lehrer & M & TV & PSB & $7 / 07 / 04$ \\
David Letterman & M & TV & CBS & $8 / 03 / 04$ \\
Jon Stewart & TV & Comedy Central & $8 / 09 / 04$ \\
\hline
\end{tabular}

interview, and the original date of the interview. The importance of these interviews can be noted in the fact that telecasts of several of them (e.g., Oprah Winfrey and David 
Letterman) have been subsequently repeated. Five of Bill Clinton's interviewers were the same interviewers as Hillary Clinton's: Katie Couric, Juan Williams, Larry King, Terry Gross, and David Letterman.

Table 2

Number and Percentage of Syllables Spoken by Bill Clinton (BC) and His Interviewer (Ier) (in Chronological Sequence, as in Table 1): Dan Rather (DR), David Dimbleby (DD), Oprah Winfrey (OW), Charles Gibson (CG), Charlie Rose (CR), Katie Couric (KC), Juan Williams (JW), Larry King (LK), Terry Gross (TG), Harry Smith (HS), Jim Lehrer (JL), David Letterman (DL), and Jon Stewart (JS)

\begin{tabular}{|c|c|c|c|c|c|}
\hline \multirow[t]{2}{*}{ Interview } & \multicolumn{3}{|c|}{ Number of Syllables } & \multicolumn{2}{|c|}{ Percentage of Syllables } \\
\hline & $\mathrm{BC}$ & Ier & $\Sigma$ & $\mathrm{BC}$ & Ier \\
\hline $\mathrm{BC} / \mathrm{DR}$ & 4,743 & 1,537 & 6,280 & 75.5 & 24.5 \\
\hline $\mathrm{BC} / \mathrm{DD}$ & 9,292 & 1,917 & 11,209 & 82.9 & 17.1 \\
\hline $\mathrm{BC} / \mathrm{OW}$ & 6,329 & 2,412 & 8,741 & 72.4 & 27.6 \\
\hline $\mathrm{BC} / \mathrm{CG}$ & 1,064 & 513 & 1,577 & 67.5 & 32.5 \\
\hline $\mathrm{BC} / \mathrm{CR}$ & 11,499 & 2,625 & 14,124 & 81.4 & 18.6 \\
\hline $\mathrm{BC} / \mathrm{KC}$ & 3,586 & 1,198 & 4,784 & 75.0 & 25.0 \\
\hline $\mathrm{BC} / \mathrm{JW}$ & 2,755 & 564 & 3,319 & 83.0 & 17.0 \\
\hline $\mathrm{BC} / \mathrm{LK}$ & 9,897 & 1,483 & 11,380 & 87.0 & 13.0 \\
\hline $\mathrm{BC} / \mathrm{TG}$ & 9,277 & 1,627 & 10,904 & 85.1 & 14.9 \\
\hline $\mathrm{BC} / \mathrm{HS}$ & 676 & 245 & 921 & 73.4 & 26.6 \\
\hline $\mathrm{BC} / \mathrm{JL}$ & 5,509 & 1,076 & 6,585 & 83.7 & 16.3 \\
\hline $\mathrm{BC} / \mathrm{DL}$ & 4,799 & 1,639 & 6,438 & 74.5 & 25.5 \\
\hline $\mathrm{BC} / \mathrm{JS}$ & 2,221 & 830 & 3,051 & 72.8 & 27.2 \\
\hline$\Sigma$ & 71,647 & 17,666 & 89,313 & 80.2 & 19.8 \\
\hline
\end{tabular}

Transcripts were prepared for all the interviews. In most cases, we could start with a rough transcript obtained from one of the media networks or channels. But in all cases, 
these transcripts served only as a preliminary guide for the preparation of accurate, detailed research transcripts. In some instances, particularly with overlapping speech, the PRAAT (www.praat.org) software was used to obtain acoustic measurements from which spoken elements could be more accurately extracted. Agreement of both authors (respectively, a native and a non-native speaker of English) was required; passages that did not meet this criterion were identified simply as an approximate number of syllables in parentheses. Syllable counts of the speech of both interviewer and interviewee were separately prepared for each interview. These are presented in Table 2 along with the percentages of syllables spoken by interviewer and interviewee in each interview.

O'Connell and Kowal (2004) was essentially an analysis of only one type of laughter - the ha-ha laughter - of Hillary Clinton herself, although some comparisons of her interviewers' laughter are included here (see Table 4 below). In the present research, the laughter of both Bill Clinton and his interviewers was analyzed. Two types of laughter were distinguished: syllables spoken laughingly as an overlay on the spoken words and the wordless ha-ha type. Onset and offset of words spoken laughingly were not easy to discern in all cases; agreement of both authors and sometimes the use of the PRAAT software were required. As in our previous research (O'Connell \& Kowal 2004: 466), we have adopted the terminology of Bachorowski, Smoski, and Owren (2001: 1583) for bouts of ha-ha laughter as "entire laugh episodes that are typically produced during one exhalation." This operational definition is to be carefully distinguished from Provine's (2000: 26): "A laugh episode consists of the comment immediately preceding laughter, and all laughter occurring within one second after the onset of the first laughter." Bachorowski et al.'s (2001) definition allows us to segregate the individual monosyllabic laugh pulses within bouts as calls of ha-ha laughter.

Table 3 presents the raw frequencies of syllables of words spoken laughingly (L), the continuous utterances $(\mathrm{U})$ in which such overlays of words spoken laughingly occur, and the corresponding syllables per response measure for both (Syl/L and Syl/U) for Bill Clinton and his interviewers for each of the interviews. Along with these, the corresponding frequencies of calls (C) and bouts (B) of ha-ha laughter and the corresponding syllables per response measure (Syl/C and Syl/B) are presented. Thus, the smaller units of both types of laughter are syllables and calls, respectively; and these combine into utterances and bouts, the longer continuous units of laughter. Because the interviewee spoke much more than the interviewers and because the interviews themselves are of varying length, the data had to be normalized as syllables per response measure in order to allow comparisons across interviews, interviewers, and the interviewee. It should be noted that the smaller units of laughter (syllables of words spoken laughingly and syllables of ha-ha calls) reflect amount of laughter more accurately than the longer units (utterances and bouts), which in turn reflect patterns of laughter rather than primarily amount of laughter. 
Table 3

Number of Syllables Spoken Laughingly (L), Number of Utterances (U) in Which These Syllables were Spoken, Number of Calls (C) and Bouts (B) of Laughter, and Syllables per Response Measure (Syl/L, Syl/U, Syl/C, and Syl/B) for Bill Clinton (BC) and Interviewers: Dan Rather (DR), David Dimbleby (DD), Oprah Winfrey (OW), Charles Gibson (CG), Charlie Rose (CR), Katie Couric (KC), Juan Williams (JW), Larry King (LK), Terry Gross (TG), Harry Smith (HS), Jim Lehrer (JL), David Letterman (DL), and Jon Stewart (JS) in their Interviews (I)

\begin{tabular}{|c|c|c|c|c|c|c|c|c|c|c|c|c|c|c|c|}
\hline \multirow[t]{2}{*}{ I } & \multirow[b]{2}{*}{ Syl/L } & \multirow[b]{2}{*}{$\mathrm{U}$} & \multirow[b]{2}{*}{ Syl/U } & \multicolumn{3}{|c|}{ Bill Clinton } & \multirow[b]{2}{*}{ Syl/B } & \multirow[b]{2}{*}{$\mathrm{L}$} & \multirow[b]{2}{*}{ Syl/L } & \multirow[b]{2}{*}{$\mathrm{U}$} & \multirow[b]{2}{*}{ Syl/U } & \multirow[b]{2}{*}{$\mathrm{C}$} & \multicolumn{2}{|c|}{ Interviewer } & \multirow[b]{2}{*}{ Syl/B } \\
\hline & & & & C & Syl/C & B & & & & & & & Syl/C & B & \\
\hline DR 87 & 55 & 13 & 365 & 27 & 176 & 16 & 296 & 0 & -- & 0 & -- & 0 & -- & 0 & -- \\
\hline DD 19 & 489 & 5 & 1,858 & 21 & 442 & 6 & 1,549 & 0 & -- & 0 & -- & 0 & -- & 0 & -- \\
\hline OW56 & 113 & 9 & 703 & 27 & 234 & 7 & 904 & 1 & 2,404 & 1 & 2,404 & 15 & 161 & 3 & 804 \\
\hline CG 0 & -- & 0 & -- & 0 & -- & 0 & -- & 0 & -- & 0 & -- & 0 & -- & 0 & -- \\
\hline CR 53 & 217 & 11 & 1,045 & 14 & 821 & 4 & 2,875 & 8 & 328 & 2 & 1,312 & 67 & 39 & 11 & 238 \\
\hline KC 32 & 112 & 2 & 1,793 & 10 & 359 & 3 & 1,195 & 0 & -- & 0 & -- & 0 & -- & 0 & -- \\
\hline JW 47 & 59 & 3 & 918 & 2 & 1,378 & 2 & 1,378 & 11 & 51 & 1 & 564 & 16 & 35 & 3 & 188 \\
\hline LK 32 & 309 & 5 & 1,979 & 4 & 2,474 & 2 & 4,948 & 0 & -- & 0 & -- & 0 & -- & 0 & -- \\
\hline TG 44 & 211 & 8 & 1,160 & 12 & 773 & 6 & 1,546 & 0 & -- & 0 & -- & 17 & 96 & 3 & 542 \\
\hline HS 0 & -- & 0 & -- & 0 & -- & 0 & -- & 0 & -- & 0 & -- & 0 & -- & 0 & -- \\
\hline JL 8 & 689 & 2 & 2,754 & 0 & -- & 0 & -- & 0 & -- & 0 & -- & 0 & -- & 0 & -- \\
\hline DL 3 & 1,600 & 2 & 2,400 & 5 & 960 & 3 & 1,600 & 1 & 1,639 & 1 & 1,639 & 92 & 18 & 12 & 137 \\
\hline JS 30 & 74 & 3 & 739 & 2 & 1,110 & 1 & 2,221 & 5 & 166 & 1 & 830 & 0 & -- & 0 & -- \\
\hline$\Sigma \quad 411$ & 174 & 63 & 1,137 & 124 & * 578 & $50 *$ & 1,433 & 26 & 679 & 6 & 2,944 & 207 & 85 & $32^{\circ}$ & 552 \\
\hline
\end{tabular}

*Of these, 7 calls $(\mathrm{Syl} / \mathrm{C}=10,235)$ and 3 bouts $(\mathrm{Syl} / \mathrm{B}=23,882)$ were articulated simultaneously with the interviewers' speech.

${ }^{\circ}$ Of these, 91 calls $(\mathrm{Syl} / \mathrm{C}=194)$ and 11 bouts $(\mathrm{Syl} / \mathrm{B}=1,606)$ were simultaneous with Bill Clinton's speech.

\section{Results}

Distribution of Speaking across Interviewee and Interviewers. Table 2 shows that the range in number of syllables per interview is 13,203 (from 921 with Harry Smith to 14,124 with Charlie Rose). The total corpus is 89,313 syllables in length. There is also a wide range of $19.5 \%$ (from $67.5 \%$ with Charles Gibson to $87.0 \%$ with Larry King) in the proportion of syllables spoken in the various interviews by Bill Clinton. His overall mean is $80.2 \%$. A significant positive rank order correlation $(r=+0.6 ; t[11]=$ $8.39 ; p<.001)$ indicates that the longer the interview in number of syllables the higher the proportion of syllables spoken by Bill Clinton.

Distribution of the Two Types of Laughter. As Table 3 indicates, laughter was used infrequently in this corpus of interviews, but in a regular fashion. Overall, laughter overlaid on spoken words (0.49\% [437/89,313] of all syllables) occurred somewhat more frequently than ha-ha laughter $(0.37 \%$ [331/89,313] of all syllables). Over both types of laughter together, Bill Clinton laughed more than 2 times (535/233 syl) as 
much as his interviewers in terms of the raw syllabic data. However, in terms of the normalized data, Bill Clinton laughed once every 134 syllables (71,647/535), whereas his interviewers laughed once every 76 syllables $(17,666 / 233)$; it should be noted that the lower syllable per response measure indices correspond to higher frequencies and vice versa. This dominance of interviewers' laughter was, however, unevenly distributed across interviewers, as the following breakdown shows (see Table 3): Seven of the 13 interviewers used no laughter at all, and two more used either calls and bouts of ha-ha laughter or syllables and utterances of words spoken laughingly, but not both. Only four of the 13 interviewers used both types of laughter (Oprah Winfrey, Charlie Rose, Juan Williams, and David Letterman). More specifically, of the total number of syllables of both types of interviewer laughter, $97.9 \%$ were produced by only five of the 13 interviewers: David Letterman (39.9\%), Charlie Rose (32.2\%), Juan Williams (11.6\%), Terry Gross (7.3\%), and Oprah Winfrey (6.9\%).

Bill Clinton on the other hand used both types of laughter in ten interviews, used only syllables and utterances of words spoken laughingly in one more, and used no laughter at all only in the two shortest interviews (with Harry Smith and with Charlie Gibson). With all frequencies normalized as syllables per response measure, it becomes clear that Bill Clinton used a syllable of laughter as overlay on his spoken words once every 174 syllables - almost 4 times as often as his interviewers. These syllables of words spoken laughingly combine into utterances used once every 1,137 syllables -- 2.6 times as often as his interviewers. The situation is the other way around with respect to calls and bouts of ha-ha laughter: His interviewers used almost 7 times as many calls and more than 2 times as many bouts of ha-ha laughter as Bill Clinton. There are two interviews in which an extreme distribution of laughter on the part of interviewer and interviewee occurred: (1) With Dan Rather, Bill Clinton had the most frequent laughter of both types in all his interviews $(\mathrm{Syl} / \mathrm{L}=55$; Syl/C $=176)$, whereas Dan Rather did not laugh at all; (2) by contrast, with David Letterman, Bill Clinton had very infrequent laughter of both types $(\mathrm{Syl} / \mathrm{L}=1,600 ; \mathrm{Syl} / \mathrm{C}=960)$, whereas David Letterman had the highest frequency of ha-ha laughter to occur in the entire corpus $(\mathrm{Syl} / \mathrm{C}=18)$.

Comparisons of Bill and Hillary Clinton's Ha-Ha Laughter. In Table 4, the subcorpus from the five interviewers common to both Hillary and Bill Clinton has been selected to allow further comparisons according to individual interviewers and within these respective interviewers. It should be noted that the data in Table 4 are limited to the ha-ha type of laughter. Despite the small number of comparisons between Hillary and Bill Clinton, no inferential statistic is needed because there is no overlap whatsoever in their frequencies (Syl/C). Hillary Clinton used 10 times as many such calls as did Bill Clinton. Our finding is in keeping with Provine's (1993: 295) assertion that "overall, females laughed more often than males." And across the board, the interviewers used almost twice as many calls of laughter with Bill Clinton as with Hillary Clinton $(52<100 \mathrm{Syl} / \mathrm{C})$, despite the fact that Katie Couric used no calls of haha laughter whatsoever in her interview with Bill Clinton. The one interviewer who must be categorized as an entertainer, performing in the presence of a live audience, rather than as a news interviewer, David Letterman, used calls of ha-ha laughter most frequently of all the interviewers with Bill Clinton (18 Syl/C) and second most frequently with Hillary Clinton (31 Syl/C). Hillary Clinton accommodated to this frequency very closely with $33 \mathrm{Syl} / \mathrm{C}$-- 29 times the frequency of such calls used by Bill Clinton (960 Syl/C). In other words, Hillary Clinton went along with the hilarity of David Letterman, Bill Clinton did not. In general, the interviewers were consistent in 
their calls of laughter across the two sets of interviews: Larry King did not laugh at all in either interview; Katie Couric and Terry Gross used very little laughter with one and none with the other interviewee; Juan Williams was intermediate in both interviews; and David Letterman laughed the most with both interviewees.

Table 4

Number of Syllables per Call (Syl/C) for Bill Clinton (BC), Hillary Clinton (HC), and the Interviewers Common to Both BC and HC: Katie Couric (KC), Juan Williams (JW), Larry King (LK), Terry Gross (TG), and David Letterman (DL)

\begin{tabular}{lcccr}
\hline Interview & \multicolumn{2}{c}{ Interviewees } & \multicolumn{2}{c}{ Interviewers } \\
& $\mathrm{BC}$ & $\mathrm{HC}$ & with BC & with $\mathrm{HC}$ \\
$\mathrm{KC}$ & 359 & 87 & -- & 629 \\
$\mathrm{JW}$ & 1,378 & 84 & 35 & 90 \\
$\mathrm{LK}$ & 2,474 & 96 & -- & -- \\
TG & 773 & 248 & 96 & -- \\
DL & 960 & 33 & 18 & 31 \\
Overall & $919=$ & $91=$ & $52=$ & $100=$ \\
& $30,314 / 33$ & $29,805 / 327$ & $6,511 / 125$ & $8,114 / 81$ \\
\hline
\end{tabular}

O'Connell and Kowal (2004) had found that Hillary Clinton used calls (C) of ha-ha laughter mostly as a back channeling while her interviewers were speaking (syl/C $=89$ ), rather than while she herself was speaking ( $\mathrm{syl} / \mathrm{C}=366$ ). By contrast, the footnote to Table 3 indicates that Bill Clinton used such back channeling of calls very seldom in the present set of interviews (syl/C $=10,235)$. His interviewers on the other hand used many more calls as back channeling (syl/C = 194). In short, Hillary Clinton's calls of laughter as back channeling occurred 115 times as often as Bill Clinton's, but only twice as often as his interviewers'. This high frequency of Hillary Clinton's use of laughter as back channeling is quite in accord with the following generalization by James and Clarke (1993: 259) regarding gender differences: "The majority of studies which have examined the use of back channel responses by listeners have found women to use more."

Amount of Laughter by Topic. Table 5 presents an overview of all the topics to which Bill Clinton and his interviewers reacted with laughter, either by speaking words laughingly or with calls of ha-ha laughter. In all, Bill Clinton used words spoken laughingly for 20 different topics, and ha-ha laughter for 18. His interviewers used words spoken laughingly for six different topics and ha-ha laughter for 13. Only two topics occasioned both kinds of laughter on the part of both Bill Clinton and his interviewers - Hillary Clinton's future candidacy for the presidency of the United States (HC President in Table 5) and The Book itself, the putative topic of all the interviews. 
Table 5

Amount of Laughter by Topic, Measured in Syllables and Utterances of Words Spoken Laughingly, and in Calls and Bouts of Ha-Ha Laughter, for Bill Clinton (BC) and His Interviewers (Iers), Ranked from Greater to Fewer of Syllables and Calls, Respectively

\begin{tabular}{|c|c|c|c|c|c|c|c|}
\hline \multirow[t]{2}{*}{ Speaker } & \multicolumn{3}{|c|}{ Words Spoken Laughingly } & \multirow[t]{2}{*}{ Rank } & \multicolumn{3}{|c|}{ Ha-Ha Laughter } \\
\hline & Topic & yllables & Utterances & & Topic & Calls & Bout \\
\hline \multirow[t]{20}{*}{$\mathrm{BC}$} & Criticisms & 76 & 9 & 1 & HC President & 23 & 7 \\
\hline & Gore Lashing & 46 & 1 & 2 & BC's Life & 22 & 7 \\
\hline & HC President & 45 & 4 & 3 & The Couch & 16 & 6 \\
\hline & BC's Life & 41 & 7 & 4 & Criticisms & 12 & 6 \\
\hline & The Couch & 37 & 8 & 5 & Chelsea & 10 & 2 \\
\hline & Other People & 32 & 8 & 6 & The Fat Kid & 8 & 2 \\
\hline & Chelsea & 28 & 3 & 7 & The Book & 5 & 3 \\
\hline & The Vacation & 18 & 2 & 8 & Interviews & 5 & 2 \\
\hline & The Book & 17 & 3 & 9 & Democrats & 4 & 2 \\
\hline & The Saxophone & 14 & 2 & 10 & White House & 3 & 2 \\
\hline & The Fat Kid & 12 & 1 & 11 & A Complimen & t 3 & 1 \\
\hline & Arafat & 11 & 3 & 12 & Enemies & 3 & 1 \\
\hline & Counseling & 11 & 2 & 13 & Arafat & 2 & 2 \\
\hline & Marijuana & 9 & 3 & 14 & Nicknames & 2 & 2 \\
\hline & Vince Foster & 3 & 2 & 15 & Powell & 2 & 2 \\
\hline & Persecution & 3 & 1 & 16 & Vince Foster & 2 & 1 \\
\hline & Politics & 2 & 1 & 17 & HC's Book & 1 & 1 \\
\hline & Rwanda & 2 & 1 & 18 & The Saxophone & 1 & 1 \\
\hline & Impeachment & 2 & 1 & 19 & & & \\
\hline & Interviews & 2 & 1 & 20 & & & \\
\hline$\Sigma$ & & 411 & 63 & & & 124 & 50 \\
\hline \multirow[t]{13}{*}{ Iers } & \multicolumn{2}{|c|}{ Surprise Question 11} & 1 & 1 & DL Comedy & 45 & 7 \\
\hline & BC's Optimism & 6 & 1 & 2 & The Book & 41 & 5 \\
\hline & Democrats & 5 & 1 & 3 & G.W. Bush & 32 & 2 \\
\hline & Kerry & 2 & 1 & 4 & Gore Lashing & 16 & 3 \\
\hline & HC President & 1 & 1 & 5 & Sandy Berger & 13 & 2 \\
\hline & The Book & 1 & 1 & 6 & BC's Life & 12 & 3 \\
\hline & & & & 7 & HC President & 12 & 2 \\
\hline & & & & 8 & The Press & 9 & 2 \\
\hline & & & & 9 & BC's Optimism & 6 & 2 \\
\hline & & & & 10 & Gore 2000 & 6 & 1 \\
\hline & & & & 11 & HC's Book & 6 & 1 \\
\hline & & & & 12 & White House & 6 & 1 \\
\hline & & & & 13 & BC's Haircut & 3 & 1 \\
\hline$\Sigma$ & & 26 & 6 & & & 207 & 32 \\
\hline
\end{tabular}


It is noteworthy that, in Hillary Clinton's interviews (O'Connell \& Kowal 2004: 469), her future candidacy for the presidency of the United States was also the topic she laughed about most of all. Furthermore, in Bill Clinton's words spoken laughingly, HC President was third in frequency, and in his calls of ha-ha laughter, first in frequency. For the interviewers, the rankings for this topic were not as salient: tied for fifth of six topics in their words spoken laughingly and tied for seventh of 13 in the calls of ha-ha laughter. In terms of overall number of syllables of both types of laughter, the topic laughed at most was HC President (81/768 syl or $10.5 \%)$, followed by The Book $(64 / 768$ or $8.3 \%)$, and by Gore Lashing (621/768 syl or $8.1 \%)$. In all, only seven topics (19\% of all 36 topics) were laughed about by both Bill Clinton and one or more of his interviewers. All the topics laughed about in the interviews of Bill Clinton, with the exception of HC President and DL Comedy, were about historical facts and are mentioned in Bill Clinton's (2004) book.

\section{Discussion}

In the introduction, we posed six questions to be engaged by our empirical data. We wish now to return to these questions.

(1) To what extent is laughter related to ongoing banal or non-banal discourse topics?

Provine (2004: 215) failed to find not only comical and humorous topics as sources of laughter, but also non-banal topics. In accord with Provine's findings, most of the 36 topics listed in Table 5 are lacking in the comical and humorous. The only clear exception is the comedy routine (DL Comedy in Table 5) of David Letterman. One such instance is the following ha-ha laughter of David Letterman (DL) after a comment on the part of Bill Clinton (BC) regarding a young woman who had sung at his inauguration:

\section{Example 1}

BC first 'n she's really great I'm

I woulda' come

$$
\begin{aligned}
& \text { DL } \\
& \text { BC and said I'd just listen to her } \\
& \text { DL } \\
& \text { UH HE HE HE all right HE HE. . }
\end{aligned}
$$

Clinton's original statement was quite serious, but he began to smile just before David Letterman's interruption and continued to smile throughout the spontaneous, unelicited ha-ha laughter. David Letterman's professional role is precisely to find everything funny, to express it in his own laughter, and thereby to elicit laughter in his audience. His laughter is a very clear manifestation of his own perspective in his role as comedian in this interview, and indeed it resulted in abundant laughter on the part of the audience.

Contrary to Provine's findings, however, most of the topics are also non-banal. One might wish to argue that topics such as The Couch, The Fat Kid, and The Saxophone are clearly banal. In this context, however, they assume a serious role of defining the life 
situations of a former president of the United States, with all the public-relations implications such roles have. This is evident from the fact that they are all discussed in Bill Clinton's (2003) book and were brought up in the questions posed by the interviewers themselves.

The following exchange between Bill Clinton (BC) and Charlie Rose (CR) clearly shows the non-banal character of their comments. It contains both words spoken laughingly and ha-ha laughter on the topic The Couch, i.e., in the context of Bill Clinton's conflict between work and the domestic scene - a very definitely non-banal topic. In all the following examples, underlining identifies syllables of words spoken laughingly. In Example 2, Bill Clinton laughs, not his interviewer:

Example 2

CR well there was also this you were gettin'beat up so bad at home that you were anxious to get to the office

BC that's right I said that uh yeah that's ri-hi-hi-hight HU HU HU HU I probably was more attentive to my work for several mo-honths just because I didn't want to have to attend to anything else

This probe on the part of Charlie Rose into the private life of Bill Clinton can perhaps be justified in that this topic had already been made public by Clinton (2004: $803 \mathrm{ff}$.) himself, both in his book and even more recently on the previous day (June 22, 2004) in his interview with David Dimbleby: “. . . it was a relief to have to go to work and concentrate on something else "cuz otherwise I would have nothing to think about all day long but what a bad fella I'd been." But the permission for the interviewers to engage this otherwise outrageously invasive reference to Bill Clinton's private life is best understood in the fact that he himself laughed about it in both interviews. By his laughter, he endowed the topic with his own perspective and made it clear that The Couch was grist for the interview mill.

It should be noted that the articulatory expansion of right to the four-syllable ri-hihi-hight and of months to the two-syllable mo-honths is fairly common in words spoken laughingly. One should also note that the ha-ha laughter is realized here in the acoustic variant of $H U H U H U H U$.

Furthermore, there is no evidence in our findings that the topics that were laughed about typically reflect an underlying "nonseriousness" or "pleasant" emotion on the part of the laugher, as Chafe (2003a: 40; see also 2003b) would insist. The grim case of Rwanda (see Example 8 below) and Clinton's laughter about it provide clear evidence of such seriousness.

The principal reason Provine was able to isolate the laughter found in his 1993 research from such non-banal topics is that his methodology did not allow him to observe them. His inclusion as "prelaugh comments" (2004: 215) of only "1 s preceding the onset of the initial laughter" (1993: 293) precluded such relevant observations. In Example 2 above, that would be a sequence such as that uh yeah that's $\underline{\text { right }}$ - a passage hardly capable of revealing anything at all regarding the topic at hand. Nor did Provine's surreptitious observations of speakers from a distance, without benefit of audio tape recording, allow any more inclusive or accurate report of verbal context. 
(2) Which of these topics are most saliently related to laughter?

The most unusual finding in Table 5 is that the single most laughed about topic was one that is neither funny in itself, nor a historical fact, nor mentioned in the book that is putatively the subject of these interviews - the future candidacy of Hillary Clinton for the presidency of the United States. Katie Couric $(\mathrm{KC})$ raised the issue of Hillary Clinton's candidacy in the following and elicited thereby two calls of ha-ha laughter (here the acoustic variant $H M H M$ ) and 20 syllables of words spoken laughingly. One should note once again that the interviewer posed the question quite seriously and without attendant laughter:

\section{Example 3}

KC political consultant Dick Morris who you thank in your book for his help has said that this book is less uh the end of a an era and more a launching pad for your wife's presidential bid for two thousand eight what do you make of that BC HM HM well I hope it's two thousand eight 'cause I hope that Senator Kerry wins this time. . .

The unavoidable implication of Clinton's response is that, even if Senator Kerry were to be elected president in 2004, Hillary Clinton would still be the Democratic candidate in 2008. This is an implicit expression of disloyalty to Senator Kerry on Bill Clinton's part. One can only speculate what the response would have meant, had it been expressed without laughter. In any event, Bill Clinton's personal perspective is clearly biased in this response in favor of Hillary Clinton, and the fact that he laughed as he spoke made it possible for him to say what he said.

As indicated in Table 5, four of the first five topics most frequently laughed about by Bill Clinton with both textual overlay and ha-ha laughter are identical: Criticisms, HC President, The Couch, and Chelsea. But the interviewers laughed at none of these topics except for HC President, and only six other topics are common to both Bill Clinton and the interviewers, though not as frequently in terms of syllables of either type of laughter: The Book (62 syl), Gore Lashing (61 syl), BC's Life (54 syl), Arafat (15 syl), White House (9 syl), and Democrats (4 syl). In short, apart from Hillary Clinton's candidacy and these six less frequent topics, Bill Clinton and his interviewers laughed about different topics. A corollary of this finding is that interviewer and interviewee generally did not laugh together in a truly dialogical fashion, but individually or monologically.

(3) To what extent does laughter occur as the ha-ha sort or, as a textual overlay?

As the summary $(\Sigma)$ bottom line of Table 3 indicates, Bill Clinton's laughter was dominantly a textual overlay on his own spoken words rather than ha-ha laughter $(411>$ 124 syl overall; columns 1 [L] and 5 [C], respectively, in Table 3). This result is noteworthy in view of the report by Nwokah, Hsu, Davies, and Fogel (1999: 880) that the "co-occurrence of speech [spoken words] and laughter has rarely been mentioned (Apte 1985; Provine 1993)" in empirical research. 
By contrast, Bill Clinton's interviewers used the ha-ha sort of laughter more commonly (207 > 26 syl overall; columns 13 [C] and 9 [L], respectively, in Table 3). In other words, Bill Clinton used laughter as an overlay on his spoken words $77 \%$ of the time (411/535 syl), whereas his interviewers used ha-ha laughter $89 \%$ of the time (207/233 syl). O'Connell and Kowal (2004: 475) found that Hillary Clinton's laughter was dominantly of the ha-ha sort as back channeling to her interviewers' ongoing speech. Whether words spoken laughingly or ha-ha laughter is to be dominant in a given instance is dependent on the speaker/listener dynamic, the setting, the context, and the topics in combination. But our findings suggest the possibility that speakers use words spoken laughingly typically when laughing about their own words, and ha-ha laughter when laughing about something said by their interlocutor.

The phonological expression of the ha-ha sort of laughter in this corpus occurred as $A H, H A, H E, H O, H A W, H M, J A$ variants, and sometimes as $U H, H U$, and various grunting sounds, both voiced and unvoiced, e.g., $H$ (unvoiced) and $K U$ (voiced). It was not unusual for several of these acoustic variants to appear in a single reply on Bill Clinton's part, e.g., $H U, H A$, and $H M$ together. Forms of ha-ha laughter are clearly not as determinate or "stereotyped" as Provine (2004: 215) has asserted. In the closing exchange of Bill Clinton's (BC) interview with Charlie Rose (CR), an example of a non-stereotyped exchange includes two phonetic variations of ha-ha laughter followed immediately by eight syllables of words spoken laughingly:

Example 4

CR My life Bill Clinton
BC HE HA HA HA HE on balance there's more good
$\underline{\text { than bad }}$

(4) Where and when does ha-ha laughter occur, i.e., during or after phrases and sentences and during speaking or during pauses?

The footnote to Table 3 indicates that a total of 98 calls $(7+91)$ of ha-ha laughter were articulated simultaneously with the interlocutors' speaking. This constitutes $30 \%(98 / 331)$ of all the calls $(124$ and $207=331$; see summaries $[\Sigma]$ of columns $5[\mathrm{C}]$ and $13[\mathrm{C}]$ in Table 3 ) in this corpus. In other words, almost a third of the calls of ha-ha laughter in this investigation were back channeling rather than punctuation during pauses at the end of phrases or sentences.

In addition to the HM HM used by Bill Clinton in Example 3 above, the first four syllables of ha-ha laughter (HE HE here) used by Oprah Winfrey (OW) were a sort of back channeling simultaneously with Bill Clinton's comments on how good the interview with her was:

\section{Example 5}

BC you were a lot better than uh most of the people that

I've had an interview with but but I don't know yet. . .

OW HE HE HE HE HE HE HE 
Provine's (1993: 296) unrestricted assertion that "laughter punctuates speech" (as it does indeed in Examples 1, 4, and 5 above) is therefore not confirmed. His overgeneralization would appear to be a consequence of the inordinate homogeneity and limited sampling of his corpus of laughter, in addition to the methodological problem already mentioned, namely his inability to note laughter accurately because of the lack of audio tape recordings. Laughter does interrupt and back channel speech.

(5) To what extent does laughter serve as a perspectival rhetorical device rather than as "an unplanned response to social, cognitive, and linguistic cues" (Provine 2004: 216)?

We have claimed that "laughter is always perspectival, i.e., it manifests some sort of position taking on the part of the laugher, even though the laughter itself is nonverbal" (O'Connell \& Kowal 2004: 476). In political media interviews, this perspectivity is not only personal, it is also socio-cultural, contextual, political, rhetorical, and strategic. The fact that Bill Clinton's interviewers do laugh is also an indication of perspectivity on their part. Clayman and Heritage (2002) insist that media interviewers exercise neutralism in their interviewing style, but interviewer laughter cannot be reconciled with such neutrality if laughter is indeed perspectival.

An instance of laughter on the part of Charlie Rose clearly shows his lack of neutralism with regard to Bill Clinton's comments. The press had disregarded some happy news about Bill Clinton's playing basketball with some inner-city boys to emphasize instead an alleged haircut while his plane held up traffic on the tarmac:

\section{Example 6}

CR it was good news

BC there wa- it was good news and they wanted to write about this alleged haircut I had but the point is
CR
HE HE HE. . .

Note too that both Bill Clinton and Charlie Rose verbalized the good news, and this verbalization on the part of Charlie Rose confirms and clarifies his subsequent laughter as an expression of non-neutralism.

As we have mentioned above, Provine (2004: 216) would likely refer to our position regarding perspectivity as "an error of intentionality" because "lawful social contingencies need not require conscious control". But this is a red herring: Level of conscious control is not the issue. Not even every aspect of language use itself is under direct conscious control. Were that the case, we would all go mad.

(6) To what extent is laughter mutually shared by interlocutors in this corpus?

Examples 1 through 6 above all show the typical situation in this corpus: Only one of the interlocutors laughed at any given juncture about a topic. Rarely do both laugh together about the same topic, either sequentially or simultaneously. The following exchange exemplifies the very infrequent occurrence of sequential laughter of interlocutors about the same topic (BC's Life) - in this case, Bill Clinton's readiness to serve in some role during Senator John Kerry's possible presidency: 
Example 7

BC ... and whatever he [Senator John Kerry] does I will support 'cause I've loved every part of my life and I've I've always got something to do I stay

CR HU

BC busy

CR HU HU what i- if he says eh if he calls you in after assuming he's elected and it's about even right now don't you think

But this is truly the exception to the rule. In general, our data show that laughter was minimally contagious in this corpus, indeed hardly mutual. Interlocutors did not pick up on the laughter of one another, nor did their messages serve to elicit laughter in one another. Perhaps the main reason for this isolation of laughter from one another is the fact that Bill Clinton's laughter was limited quite generally to topics in which he himself had played a specific type of role. If the 27 topics in Table 5 about which he laughed are compared with a list of other topics that were discussed, but in an entirely sober fashion without any trace of laughter, a pattern emerges. The non-laughable list would include all of the following topics: Ken Starr, Osama bin Laden, al Qaeda, USS Cole, Paula Jones, Monica Lewinsky, and 9/11. We submit that there are two motives operating in the non-laughter relative to this list. Bill Clinton is not yet finished with some of these topics; they are still a thorn in his side, and he does not wish to engage them more than absolutely necessary. He is sober as a judge in addressing the Monica Lewinsky topic. And some of these topics are simply remote; they did not impinge on him directly. The topics he laughed at, however, are all matters that have impinged on him personally. What Kakutani (2004) wrote of Bill Clinton's self-presentation in his book, seems to apply equally to his laughter: It is "self-indulgent" (A1), "self-serving" (A25), and "self-absorbed" (A25). Similarly, in a German review by Wergin (2004: 7), the presentation of Bill Clinton in his book was described as "selbstverliebt" (literally, "in love with himself"). In his laughter in these interviews, he presented himself in the same light as in his book.

There are two topics about which Bill Clinton seems to have laughed inappropriately. Both had to do with tragic deaths. The first of these is his brief and defensive laughter about a truly ugly situation of genocide in Rwanda, even after he had begun his answer with "Let me try to give a serious answer to that." David Dimbleby's reaction does not appear sympathetic to Bill Clinton:

\section{Example 8}

BC ... as I say over and over again it's [the genocide in Rwanda] one of my greatest regrets but we look at it backwards and say well I had to know that seven or eight hundred thousand people could be killed with machetes in ninety da-hays and as far as I know there's no precedent for that in the history of the world

DD but the Red Cross was warning that this was happening all the time

There is no evidence of grimness or anger in Example 8. Instead, Bill Clinton seems here to laughingly ridicule the expectation on the part of some people that he could have 
foreseen such an unlikely event as the murder by machete of hundreds of thousands of people within ninety days. In other words, he uses very brief laughter (2 syl) strategically in this instance to distance himself from an untenable position.

Another instance of laughter that, at least at first blush, would appear to be inappropriate, occurs in Bill Clinton's report to Larry King on his last telephone call with Vince Foster before Foster committed suicide:

\title{
Example 9
}

\begin{abstract}
LK did you know he was depressed
BC yes and no I knew that he was upset and ironically the night before he killed himself tsk I called him because I knew he had been really upset because the Wall Street Journal was saying all these terrible things about him it was all a bunch of hooey bit they were saying it but only on the editorial page and I called him and I said $\underline{\mathrm{V}-\mathrm{HU}} \mathrm{HU} \underline{\mathrm{V} \text {-hince hardly }}$ anybody reads the editorial page of the Wall Street Journal. . .
\end{abstract}

In this instance, the inappropriateness of Bill Clinton's laughter is perhaps diminished insofar as he was citing his own conversation with Vince Foster. The point must be made that Clinton had found the matter funny at the time of the phone conversation; it was not that he was embarrassed about what he was saying. That conversation occurred before Bill Clinton knew about Vince Foster's suicide; he was trying to cheer Foster up. Once the listener or reader appreciates the personal perspective from which Bill Clinton was speaking, his rationale becomes explicable, namely his effort to authentically reproduce his phone conversation with Vince Foster. But without such privileged insight on the part of a listener, Bill Clinton's laughter here remains indeed astonishingly incongruous.

It should also be noted that the interjection tsk in the third line of Example 9 was not used there as "an expression of denial" (Merriam-Webster's collegiate dictionary, $11^{\text {th }}$ ed., 2003: 1345). It is simply a dental click used habitually by Bill Clinton in transitional situations. In this instance, the transition was from a presentation of Vince Foster's perspective to a presentation of Bill Clinton's engagement of the situation. Generally, $t s k$ gives the impression of reflectiveness.

And finally, an exchange between Dan Rather and Bill Clinton appears to manifest a profound disrespect on the part of Bill Clinton for both Yassir Arafat and his culture. As a colleague who is Palestinian herself expressed it (C. Suleiman, personal communication, November 2004), the greeting with a kiss on each cheek is an important part of Arafat's culture. Clinton's merriment over the avoidance of such a form of greeting in favor of the handshake was indeed insulting:

Example 10

BC it seems so easy now how they'd do that but at the time it was revolutionary you know the idea that they were gonna come and sign a deal together before the whole world
DR
and even shake hands
BC
yeah so first thing we

had to deal with was were they gonna shake hands at all and I could tell Rabin 
didn't want to do it the Arafat was very much unpopular very unpopular in Israel JA I said to him I said uh we were talking I said Yitzhak you know you're gonna shake his hand and he says no oof. . .

With regard to all these incongruous instances of laughter, one must add that neither cynicism nor inappropriateness is necessarily the equivalent of strategic inefficiency. There is no reason why they cannot be quite functional in one or another of these interview contexts. However, the the preceding Arafat in the third last line of Example 10 was not at all functional; it was simply an anomalous false start uttered momentarily by Bill Clinton.

Bill Clinton's comments about laughter along with his attendant laughter provide us with a meta-level of consideration. It is not by accident that both his comments about laughter in these interviews accompany the topic of The Couch, i.e., his exclusion from the marital bed in the aftermath of the Monica Lewinsky scandal. The first is with David Dimbleby:

\section{Example 11}

DD and you as you describe were kicked out of the marital bed and living on the couch

BC HO I was HA HA HA

DD while you were while you were doing this thing (+ 4 syllables)

BC true I laugh about it now but it's true it's the it's true

The second instance is with Oprah Winfrey:

\section{Example 12}

BC but it was a pretty comfortable couch and I think I thought maybe I ought to be on it I don't know but I stayed on it for over two months

OW hm over two month and at what point you you you you write in the book about Hillary starting to laugh again was that the point that you know maybe I can move off the couch

BC yeah she was laughin' she started laughin' again well the whole thing was so inherently absurd I mean no no uh well first of all we made a decision and it was mostly hers in the beginning that we would try to save our marriage. .

It should be noted that The Couch is not one of those topics that Bill Clinton is not yet finished with. The marriage rift has been put behind them, and they are both now able to laugh about the situation, both as past and as settled.

Four of the interviews of Bill Clinton ended in laughter on his part: Charlie Rose (see Example 4) and Terry Gross did not join in the laughter at this point, though they had laughed heartily in the course of their interviews. And David Dimbleby was sober as a judge, as he was throughout the interview, while Bill Clinton laughed about his role in the White House, were Hillary Clinton to become president. The contrast is thunderous: 
Example 13

DD and they'll be getting two for the price of one

BC yeah we tried that before and it didn't work out

so well I think I'll just pour tea HA HA HA HA HA HA

DD mister president thank you

BC thanks actually it did work out very well for the country

HA HA HA HA HA HA

Oprah Winfrey was the only one of these four who joined Bill Clinton's laughter toward the end of the interview. And it was predictably about his possibly becoming the first "first husband" during a presidency of Hillary Clinton:

Example 14

OW ok and what what have you thought about what it would be like to be the first husband

BC UH HUH no but I uh I would do whatever uh the duties require HU HU HU HU HU HU whatever was required I would do HU HU HU HU OW HEE HU HU HU HU HU HU HU yeah HU HU HU HU

And so, at the end of their interviews, David Dimbleby and Oprah Winfrey (Examples 13 and 14) provide extreme examples of sobriety and hilarity respectively in response to Bill Clinton's laughter.

\section{Conclusions}

We have claimed in this article that Bill Clinton uses laughter in his interviews as a deliberate and sophisticated rhetorical device. One might argue that such an intentional use of laughter to guide or influence an audience demands an additional analysis of audience responses. Such an argument is in accord with research by Atkinson (1984a \& b), who discussed audience reactions (including laughter and applause) to politicians' speeches. However, in the corpus of radio and TV interviews analyzed in the present research, there was, for the most part, no audience present in the studio, and hence, immediate audience reactions were not available. Bill Clinton's sole immediate audience in all but two of these interviews was the interviewer. Therefore, our arguments for the intentional use of laughter as a rhetorical device must rely on our analyses of the performance of Bill Clinton and his interviewers.

As a first step in our argument, we wish to remind the reader that the 13 interviews in our corpus took place not as a consequences of any specific political action on the part of former president Bill Clinton, but because he had just published his memoirs $M y$ life (2004). What is quite obvious is the fact that the public - as represented by the interviewers and their questions - was interested primarily in how Clinton was going to react to questions about the scandals surrounding his personal life. Under these 
circumstances, one could hardly expect ahead of time that his response would be laughter as a rhetorical coping device.

Our analyses of the two types of laughter have shown that Bill Clinton used laughter mostly as an overlay on his spoken words and less frequently in the ha-ha mode $(411>$ $124 \mathrm{syl})$, whereas his interviewers laughed more in the ha-ha mode than as an overlay on their own words $(162>26 \mathrm{syl})$. A chi square statistic found these two distributions to be significantly different $\left(\chi^{2}[d f=1]=230.88, p<0.001\right)$, even after the exclusion of 45 syllables of David Letterman's ha-ha laughter for the sake of a more conservative estimate of the frequency of interviewers' ha-ha laughter. We have claimed above that speakers typically use laughter as an overlay on their words when they laugh about what they themselves are saying, but use ha-ha laughter when they laugh about what their interlocutors are saying. The former is exactly what Bill Clinton typically does; the latter, what his interviewers typically do.

Table 6

Topics of Laughter from Table 5 Consolidated Generically; Number (\#) and Percentage (\%) of Syllables of Laughter Overlaid on Words (W) and Calls of Ha-Ha Laughter for Bill Clinton (BC) and his Interviewers

\begin{tabular}{|c|c|c|c|c|c|c|c|c|}
\hline \multirow[b]{2}{*}{ Topics } & \multicolumn{2}{|c|}{ Bill Clinton } & \multicolumn{2}{|c|}{$\Sigma$} & \multicolumn{2}{|c|}{ Interviewers } & \multicolumn{2}{|c|}{$\Sigma$} \\
\hline & Words & На-На & \# & $\%$ & Words & $\mathrm{Ha}-\mathrm{Ha}$ & \# & $\%$ \\
\hline \multicolumn{9}{|c|}{ BC's Personal } \\
\hline Problems & 171 & 40 & 211 & 39.4 & -- & 3 & 3 & 1.6 \\
\hline \multicolumn{9}{|c|}{ BC's Personal } \\
\hline Life & 83 & 36 & 119 & 22.2 & 6 & 18 & 24 & 12.8 \\
\hline Politics & 95 & 20 & 115 & 21.5 & 18 & 88 & 106 & 56.4 \\
\hline \multicolumn{9}{|l|}{ Hillary } \\
\hline Presidency & 45 & 23 & 68 & 12.7 & 1 & 12 & 13 & 6.9 \\
\hline BC's Book & 17 & 5 & 22 & 4.1 & 1 & 41 & 42 & 22.3 \\
\hline$\Sigma$ & 411 & 124 & 535 & 100 & 26 & $162 *$ & 188 & 100 \\
\hline
\end{tabular}

*Exclusive of 45 instances of ha-ha laughter on the part of David Letterman

The next step in our logic is to ask whether the laughter of Bill Clinton and his interviewers is systematically related to specific topics. In order to engage this question, a generic consolidation of the laughter topics from Table 5 is presented in Table 6 . The topic BC's Book has been included to cover separate discussions of its preparation and marketing. There we find that Bill Clinton laughs mainly about his personal problems 
(39.4\% of all his laughter syllables) and his personal life (22.2\%), whereas his interviewers seldom laugh about these topics (1.6\% and 12.8\%). Instead, they laugh mainly about politics (56.4\%) and Bill Clinton's book (22.3\%), whereas he laughs about these topics much less frequently $(21.5 \%$ and $4.1 \%)$. Even though Hillary Clinton's presidency is the single topic (see Table 5) that is most frequently laughed about, Bill Clinton laughs about it twice as much (12.7\%) as do his interviewers $(6.9 \%)$. There is, in fact, a negative Spearman rank-order correlation of $r=-0.5$ between Bill Clinton's and his interviewers' amount of laughter about the generic topics listed in Table 6.

Laughter overlaid on words is semantically transparent and hence constitutes a deliberate and explicit commitment on the part of the speaker, whereas ha-ha laughter does not present an intrinsic semantic rationale and remains accordingly safely opaque for the laugher, in this case primarily the interviewer. Whereas laughter overlaid on words is strategically forthright, ha-ha laughter is reactive and noncommittal. Put another way, the 129 syl $(129 / 188=68.6 \%)$ of ha-ha laughter about politics and Bill Clinton's book are safe for the interviewers; more than 3 syl (1.6\%) of ha-ha laughter about Bill Clinton's personal problems would have been gauche and inappropriate on their part. Whereas Bill Clinton can afford to show himself as self-absorbed in his laughter, his interviewers dare not indulge these same issues laughingly.

An additional way of looking at rhetorical strategies that are realized with the help of laughter is to analyze the examples we cite in the course of this article. Three of our examples (7, 14, and 15 [see below]) exhibit laughter on the part of both Bill Clinton and his interviewers, three more $(1,5$, and 6$)$ exhibit laughter on the part of only the interviewer. That leaves nine examples in which only Bill Clinton laughs. And these are the ones that most clearly manifest the function of laughter for intentional strategic purposes. Fully six of these nine examples deliberately foster the preservation of a threatened positive self-presentation on the part of Bill Clinton (Examples 2, 4, 7, 11, 12, and 13) - a sort of damage control, as we have seen above, for his personal problems. For instance, Examples 2, 11, and 12 are all efforts on the part of Bill Clinton to recast in a better light - with the help of his own laughter -- what had just been described by an interviewer as a disastrous marital situation.

All these findings are compatible with a concept of laughter as "any audible sound that an ordinary person would characterize as a laugh if heard under everyday circumstances" (Bachorowski et al. 2001: 1581). In addition, the meticulous acoustic analyses of Bachorowski et al. (see also Bachorowski \& Owren 2001: 256) confirm the lack of stereotypy found in our own data; instead, ha-ha laughter is notable for "its acoustic variability" - "a repertoire of sounds" (1596). They add that laughter is used "nonconsciously but strategically" (1596). We would agree and would reiterate that laughter, though in itself nonverbal, may also be used as a deliberate, sophisticated, rhetorical device to accomplish a goal. Glenn (2003: 168) corroborates this function of laughter as follows:

The choice to laugh or not laugh may display acceptance of or resistance to some definition-ofsituation proposed by other. . . . Although not possessing linguistic or semantic content, laughs still allow for varied, nuanced, and subtle displays of definitions of situation.

Still, Provine (2004: 215) insists that laughter is "unconsciously controlled," and Chafe (2003a: 39) chimes in that laughter, as an expression of "the feeling of nonseriousness," is "not under voluntary control." Apte (1985: 240) had it right: Laughter "is at times an involuntary reflex action and at times occurs intentionally." At one extreme, the 
youngster whose tummy is tickled responds with an involuntary belly laugh, whereas, at the other extreme, a lawmaker who responds to an adversary's humor on the floor of Congress does so with great deliberateness and voluntarily controlled laughter. Context makes a notable difference as to which type is to emerge: In a relaxed setting with one's drinking companions, spontaneity is to be expected, whereas a socially delicate situation that might require considerable diplomacy may elicit only intentional laughter. For example, Bill Clinton's rhetorical strategy of laughing when presented with a noncomplimentary interpretation of some behavior from his past is generally an intentional type of laughter, as in Example 2 above. Therein, Clinton' marital situation is described by the interviewer as disastrous, and Clinton replies with a "that's right" and then extensive laughter. It does indeed appear that Bill Clinton frequently laughs intentionally when speaking about delicate or embarrassing personal issues.

In field-observational research, it is extremely difficult to individually discern such cases with certainty. In any event, the will is not of itself a faculty of consciousness, and, as William James (1890, vol. 2: 486) said long ago, "The only direct outward effects of our will are bodily movements." Were we focally, deliberately conscious of all aspects of our use of language itself, we would indeed go mad.

To return to the notion of stereotypy, there appear to be a number of roots for the conviction that laughter is "a highly stereotyped response pattern" (Sroufe \& Wunsch 1972): (1) A tradition in modern psychology goes back as far as Washburn (1929); it springs from an emphasis on the laughter of infants in their very early development. The fact is that such early laughter has not yet been overlaid with the complexities and nuances of language habits, social restrictions, and cultural imperatives, and is inevitably more primitive and less differentiated. (2) A similar tradition reaches back to Darwin's (1872) evolutionary framework, in which the primitive roots of laughter are emphasized. (3) Another tradition is the emphasis on ha-ha laughter only, to the exclusion of laughter as an overlay on spoken words (e.g., Provine 1993). It is clearly through the integration of laughter with spoken language that its subtle usage as a deliberate, sophisticated, and rhetorical device is to be seen most clearly. And (4) finally, the alleged stereotypy of laughter is one more consequence of The written language bias in linguistics (Linell 1982). The very fact that we characterize laughter in writing as ha-ha laughter reveals this bias. And the practice of novelists and cartoonists of characterizing laughter as ha-ha in the written modality exemplifies this bias in our everyday use of language.

The laughter found in these interviews of Bill Clinton was for the most part what we would refer to as monological: Interviewer and interviewee did not laugh together, either sequentially or simultaneously (Examples 7, 14, and 15 are exceptions: about Bill Clinton's possible job with a President Kerry, about his possibly becoming the first "first husband," and about the hypothetical Gore Lashing, respectively). Instead, they laughed about different topics at different times. We close with a notable exception to this finding. Bill Clinton and his interviewer Juan Williams laughed together in this instance, in an eminently dialogical fashion about the Gore Lashing:

Example 15

BC yeah first of all one night as I was sayin' this in the book one night I told him I said look Al if I thought it would help you I'd go down to the steps of the Washington Post and let you lash me with a bullwhip

and 


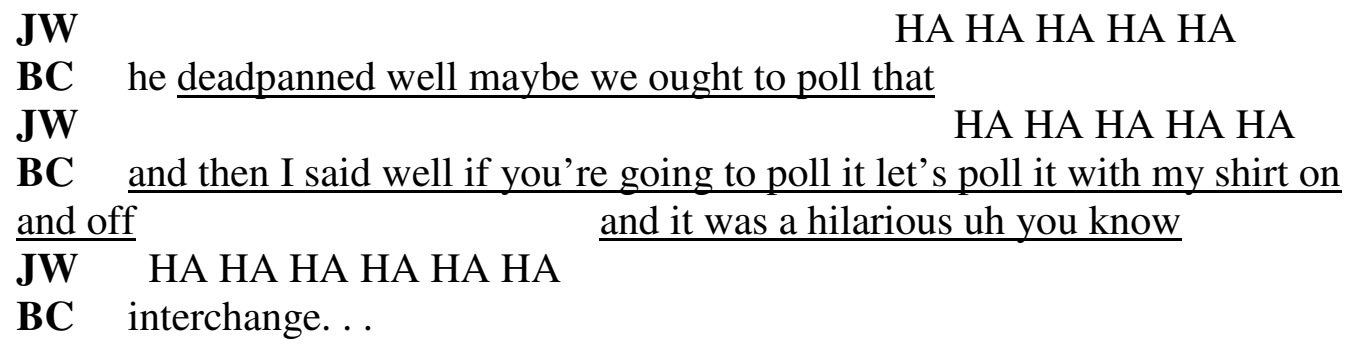

It is also to be noted that there is no admixture in Example 15 of words spoken laughingly and ha-ha laughter: Bill Clinton specialized in the former, Juan Williams in the latter. And even the ludicrous hypothetical situation laughed about here served Bill Clinton well to make a serious political point and thereby to express his own personal perspective as a supporter of Gore's presidential candidacy.

The most publicized research on laughter in the first decade of the twenty-first century has been that of Robert Provine (2000, 2004). His methodology has almost entirely excluded consideration of any non-banal topics related to the elicitation of laughter. With his window of one second before the onset of ha-ha laughter (Provine 1993), he has effectively excluded context of any but the most banal sort.

Pace Bergson (1914) and other traditional scholars, laughter is not synonymous with the comical or humorous. But it is a powerful political and social tool for revealing personal perspective - and a sufficiently complex one to warrant a great deal more research.

The dust jackets of both Hillary Clinton's (2003) and Bill Clinton's (2004) books show them smiling: Hillary with open mouth (the risus dentium; see also the dust jackets of Glenn 2003 and Provine 2000) and Bill Clinton with closed mouth. The differential smiles suggest that they might also laugh differently, as indeed they do.

\section{References}

Atkinson, M. (1984a) Our masters' voices: The language and body language of politics. London: Methuen.

Atkinson, J.M. (1984b) Public speaking and audience responses: Some techniques for inviting applause. In J.M. Atkinson \& J. Heritage (eds.), Structures of social action: Studies in conversation analysis. Cambridge: Cambridge University Press, pp. 370-409.

Apte, M.L. (1985) Humor and laughter: An anthropological approach. Ithaca, NY: Cornell University Press.

Bachorowski, J.-A., \& M.J. Owren (2001) Not all laughs are alike: Voiced but not unvoiced laughter readily elicits positive affect. Psychological Science 12: 252-257.

Bachorowski, J.-A., M.J. Smoski, \& M.J. Owren (2001) The acoustic features of human laughter. Journal of the Acoustical Society of America 110: 1581-1597.

Bergson, H. (1914) Laughter: An essay on the meaning of the comic (trans. C. Brereton \& F. Rothwell). New York: Macmillan.

Bohrer, K.H., \& K. Scheer (eds.) (2002) Lachen: Über westliche Zivilisation. Stuttgart: Klett-Cotta. 
Chafe, W. (2003a) Laughing while talking. In D. Tannen \& E. Alatis (eds.), Georgetown University round table on languages and linguistics 2001. Linguistics, language, and the real world: Discourse and beyond. Washington, DC: Georgetown University Press, pp. 36-49.

Chafe, W. (2003b, July) Importance of not being earnest. Paper presented at the meeting of the International Society for Humor Studies. Chicago, IL.

Chapman, A.J. (1976) Social aspects of humorous laughter. In A.J. Chapman \& H.C. Foot (eds.), Humour and laughter: Theory, research and applications. London: Wiley, pp. 155-185.

Clayman, S., \& J.Heritage (2002) The news interview: Journalists and public figures on the air. Cambridge: Cambridge University Press.

Clinton, B. (2004) My life. New York: Alfred A. Knopf.

Clinton, H. (2003) Living history. New York: Random House.

Coser, R.L. (1960) Laughter among colleagues: A study of the social functions of humor among the staff of a mental hospital. Psychiatry 23: 81-95.

Darwin, C. (1872/1965) The expression of emotions in man and animals. Chicago: University of Chicago Press.

Foot, H.C., \& A.J. Chapman (1976) The social responsiveness of young children in humorous situations. In A.J. Chapman \& H.C. Foot (eds.), Humor and laughter: Theory, Research and Application. London: Wiley, pp. 141-175, 187-214.

Freud, S. (1905/1976) Jokes and their relation to the unconscious (trans. J. Strachey). Harmondsworth, UK: Penguin.

Glenn, P. (2003) Laughter in interaction. Cambridge: Cambridge University Press.

Harris, C.R. (1999) The mystery of ticklish laughter. American Scientist 87: 344-351.

Hooff, J.A.R.A.M. van (1972) A comparative approach to the phylogeny of laughter and smiling. In R.A. Hinde (ed.), Nonverbal communication. Cambridge: Cambridge University Press, pp. 209-241.

James, D., \& S. Clarke (1993) Women, men, and interruptions: A critical review. In D. Tannen (ed.), Gender and conversational interaction. New York: Oxford University Press, pp. 231-280.

James, W. (1890) The principles of psychology. (vols. 1 and 2). New York: Henry Holt.

Jefferson, G. Some features of the serial construction of laughter. Unpublished manuscript, University of Massachusetts, Amherst.

Jefferson, G. (1974) Notes on the sequential organization of laughter in conversation: Onset sensitivity in invitations to laugh. Paper presented at the American Anthropological Association Convention, Mexico City.

Jefferson, G. (1979) A technique for inviting laughter and its subsequent acceptance declination. In G. Psathas (ed.), Everyday language: Studies in ethnomethodology. New York: Irvington, pp. 79-96.

Kakutani, M. (2004, June 20) The pastiche of a presidency, imitating a life, in 957 pages. New York Times, A1, A25.

Keltner, D., \& G.A. Bonanno (1997) A study of laughter and dissociation: Distinct correlates of laughter and smiling during bereavement. Journal of Personality and Social Psychology 73: 687-702. 
Kluger, J. (2005, January 17) The funny thing about laughter. Time 165: A25, A26, \& A29.

Koestler, A. (1964) The act of creation. London: Hutchinson.

Kuschel, K.-J. (1994) Laughter: A theological essay (trans. J. Bowden). New York: Continuum.

Linell, P. (1982) The written language bias in linguistics. Linkőping, Sweden: University of Linkőping.

Merriam-Webster's collegiate dictionary (11 ${ }^{\text {th }}$ ed.) (2003) Springfield, MA: Merriam-Webster.

Nwokah, E.E., H.-C. Hsu, P. Davies, \& A. Fogel (1999) The integration of laughter and speech in vocal communication: A dynamic systems perspective. Journal of Speech, Language, and Hearing Research 42: 880-894.

O’Connell, D.C., \& S. Kowal (2004) Hillary Clinton's laughter in media interviews. Pragmatics 14: 463478.

Provine, R.R. (1993) Laughter punctuates speech: Linguistic, social and gender contexts of laughter. Ethology 95: 291-298.

Provine, R.R. (2000) Laughter: A scientific investigation. New York: Penguin.

Provine, R.R. (2004) Laughing, tickling, and the evolution of speech and self. Current Directions in Psychological Science 13: 215-218.

Psathas, G. (ed.) (1979) Everyday language: Studies in ethnomethodology. New York: Irvington.

Sroufe, A., \& J.P. Wunsch (1972) The development of laughter in the first year of life. Child Development 43: 1326-1344.

Stearns, F.R. (1972) Laughing: Physiology, pathophysiology, psychology, pathopsychology, and development. Springfield, IL: Charles C. Thomas.

Trouvain, J. (2001) Phonetic aspects of "speech laughs.” In C. Cave, I. Guaitella, \& S. Santi (eds.), Oralité et Gestualité: Actes du colloque ORAGE, Aix-en-Provence. Paris: L'Harmattan, pp. 634-639.

Trouvain, J. (2003) Segmenting phonetic units in laughter. In M.J. Solé, D. Recasens, \& J. Romero (eds.), Proceedings of the $15^{\text {th }}$ International Congress of Phonetic Sciences. Barcelona: Universitat Autònoma de Barcelona, pp. 2793-2796.

Washburn, R.W. (1929) A study of the smiling and laughing of infants in the first year of life. Genetic Psychology Monographs 6: 397-535.

Wergin, C. (2004, August 2) Liebt mich doch. Der Tagesspiegel, 7.

White, C.L. (1988) Liberating laughter: An inquiry into the nature, content, and functions of feminist humor. In B. Bate \& A. Taylor (eds.), Women communicating: Studies of women's talk. Norwood, NJ: Ablex, pp. 75-90. 